\title{
Association of the thyroid hormone responsive spot 14 alpha gene with growth-related traits in Korean native chicken
}

\author{
Muhammad Cahyadi', Hee-Bok Park ${ }^{2}$, Dong Won Seo ${ }^{3}$, Shil Jin ${ }^{3,4}$, Nuri Choi ${ }^{5}$, Kang Nyeong Heo ${ }^{6}$, \\ Bo Seok Kang ${ }^{6}$, Cheorun Jo ${ }^{7}$, and Jun Heon Lee ${ }^{3, *}$
}

\footnotetext{
* Corresponding Author: Jun Heon Lee Tel: +82-42-821-5779, Fax: +82-42-825-9754 E-mail: junheon@cnu.ac.kr

${ }^{1}$ Department of Animal Science, Faculty of Agriculture, Universitas Sebelas Maret, Surakarta 57126, Indonesia

2 Department of Animal Resources Science, Kongju National University, Yesan 32439, Korea ${ }^{3}$ Department of Animal and Dairy Science, College of Agriculture and Life Sciences, Chungnam National University, Daejeon 34134, Korea

${ }^{4}$ Hanwoo Research Institute, National Institute of Animal Science, RDA, Pyeongchang 25340, Korea ${ }^{5}$ Division of Biotechnology, College of Environmental and Bioresource Sciences, Chonbuk National University, Iksan 54596, Korea

${ }^{6}$ Poultry Research Institute, National Institute of Animal Science, RDA, Pyeongchang 25340, Korea ${ }^{7}$ Department of Agricultural Biotechnology and Research Institute of Agriculture and Life Science, Seoul National University, Seoul 151921, Korea
}

ORCID

Muhammad Cahyadi

https://orcid.org/0000-0003-3300-6479 Hee-Bok Park

https://orcid.org/0000-0002-9418-1898 Dong Won Seo

https://orcid.org/0000-0003-0548-7068 Shil Jin

https://orcid.org/0000-0003-1120-3631 Nuri Choi

https://orcid.org/0000-0002-5526-5124 Kang Nyeong Heo

https://orcid.org/0000-0002-2757-4333

Bo Seok Kang

https://orcid.org/0000-0002-8170-6376 Cheorun Jo

https://orcid.org/0000-0003-2109-3798 Jun Heon Lee

https://orcid.org/0000-0003-3996-9209

Submitted Jul 3, 2019; Revised Sept 9, 2019; Accepted Feb 10, 2020
Objective: Thyroid hormone responsive spot 14 alpha (THRSP) has been used to investigate the regulation of de novo lipogenesis because the variation of THRSP mRNA content in the tissue affects directly the ability of that tissue to synthetize lipids. Also, this gene responds to thyroid hormone stimulation and high level of carbohydrate feeding or insulin-injection. This study was carried out to investigate variations within THRSP and their effects on body and carcass weights in Korean native chicken (KNC).

Methods: A total of 585 chickens which represent the five lines of KNC (Black, Gray-Brown, Red-Brown, White, and Yellow-Brown) were reared and body weight data were recorded every two weeks from hatch until 20 weeks of age. Polymerase chain reaction- restriction fragment length polymorphism, DNA chips for Agilent 2100 Bioanalyzer, and Fluidigm Genotyping Technology, were applied to genotype selected markers. A linear mixed-effect model was used to access association between these single nucleotide polymorphism (SNP) markers and growth-related traits.

Results: A total of 30 polymorphisms were investigated in THRSP. Of these, nine SNPs for loci were selected to perform association analyses. Significant associations were detected between g.-49G > T SNP with body weight at 20 weeks of age (BW20), g.451T>C SNP with growth at 10 to 12 weeks of age (GR10-12), and g.1432A>C SNP with growth at 14 to 16 weeks trait (GR14-16) and body weight at 18 weeks of age (BW18). Moreover, diplotype of the THRSP gene significantly affected body weight at 12 weeks of age (BW12) and GR10-12 traits. Diplotype of ht1/ht2 was favorable for BW12 and GR10-12 traits.

Conclusion: These results suggest that THRSP can be regarded as a candidate gene for growth traits in KNC.

Keywords: Body Weight; Growth; Korean Native Chicken; Association; Thyroid Hormone Responsive Spot 14 Alpha Gene

\section{INTRODUCTION}

Korean native chicken (KNC) is an important genetic resource in Korea. The KNC conservation program was launched by the National Institute of Animal Science in 1994 [1,2]. After the two decades of the conservation program's duration, the five lines of KNC, which are distinguished by plumage color, have been established and successfully released in the Korean market and are 2 to 3 times more expensive than commercial broilers [3,4]. The advantages of $\mathrm{KNC}$ in Korean market are that they have higher protein and lower fat contents compared to commercial broiler. However, like most indigenous chicken breeds, KNC have a relatively slower growth performance that implies a longer rearing time $[1,3]$. The heritability value $\left(h^{2}\right)$ of growth traits of KNC is high at an early age and becomes low to moderate as the chickens age [5]. Therefore, breeding strategies based on either quantitative 
or molecular genetics to improve growth performance of $\mathrm{KNC}$ are required.

Body weight in chickens can be easily observed and measured [6]. However, it is a direct indicator of growth which is a complex, and highly orchestrated phenomenon involving multiple genetic factors and environmental conditions with a host of different hormones and their receptors in various tissues [7]. Hence, it is not surprising that most of growthrelated traits are regarded as complex quantitative traits.

Regulation of body weight has been an interesting topic to investigate since it is tightly related to obesity, it requires an understanding of lipid metabolism and energy balance processes [8-11]. Lipid synthesis involves multiple genes in highly complicated and integrated processes since they will maximize the storage of energy when food nutrients are abundant and repress energy expenditure when nutrients are restricted. Thyroid hormone responsive spot 14 (THRSP) gene, which is widely studied as a model of de novo lipogenesis regulation, encodes a small acidic THRSP protein. This protein acts as a transcription factor involved in control of lipogenic enzymes since it responds to thyroid hormone stimulation [1214]. It is located in the chromosomal region affecting obesity susceptibility, and its expression is increased by carbohydrate feeding or insulin-injection [15]. In humans, THRSP is associated with obesity, growth and differentiation of breast cancer cells [16,17]. In chickens, THRSP was firstly analyzed by Cogburn et al [18] using microarray analysis that showed a differential expression of the THRSP sequence tag in liver of chickens genetically selected for fast or slow growth rate. It was mapped at 1q41-44 [19], where the quantitative trait locus (QTL) region for abdominal fat yield, skin fatness, and abdominal fatness were found [20-22]. The polymorphisms within this gene have been investigated using polymerase chain reaction-restriction fragment length polymorphism (PCR-RFLP) approach which revealed that they were associated with growth-related and fatness traits in chicken $\mathrm{F}_{2}$ intercross pedigrees $[23,24]$. Hence, the objective of this study was to investigate polymorphisms of THRSP and to evaluate their effects on the growth-related traits in KNC.

\section{MATERIALS AND METHODS}

\section{Animal resources and DNA extraction}

A total of 585 individuals of KNC (282 males and 303 females) comprising $68 \mathrm{~F}_{1}$ nuclear families ranging in size from 3 to 20 chickens were used in this study. They were divided into five lines on the basis of plumage colors (Black, 88; Gray-Brown, 110; Red-Brown, 135; White, 122; and Yellow-Brown, 130) [25]. They were reared under controlled feeding and environmental conditions in the National Institute of Animal Sciences (NIAS), Republic of Korea. This study was also performed to meet recommendations described in "The Guide for the Care and Use of Laboratory Animals" published by the Institutional Animal Care and Use Committee of the National Institute of Animal Science (2012-C-037) in Korea. Body weights were measured at every two weeks from hatch to 20 weeks of age. Descriptive statistics of body weight and growth-related traits in the KNC population can be found elsewhere [26].

For the molecular genetic analysis, blood samples were taken from wing veins using $3 \mathrm{~mL}$ tubes containing ethylenediaminetetraacetic acid. Moreover, these blood samples were processed to isolate genomic DNA according to the method described by Miller et al [27]. The DNA concentration was measured using NanoDrop 2000c UV-Vis Spectrophotometer (Thermo Fisher Scientific Inc., Waltham, MA, USA). Isolated DNA genome was stored in the refrigerator at $-20^{\circ} \mathrm{C}$ to maintain DNA quality until used.

\section{Polymerase chain reaction and genotyping}

Three pairs of primer sets and restriction enzyme information used in this study are shown in Supplementary Table S1. Two primers were designed using primer3 version 0.4.0 (http:// frodo.wi.mit.edu/primer3/) based on GenBank reference NC_006088.3, and a primer pair for 9-bp indel detection that was previously reported by Wang et al [15]. The PCR was carried out in $20 \mu \mathrm{L}$ volume containing 25 ng per $\mu \mathrm{L}$ DNA genome, $0.8 \mu \mathrm{L}$ each primer, $1.6 \mu \mathrm{L} 10 \mathrm{mM}$ dNTP, $2.0 \mu \mathrm{L}$ $10 \times$ reaction buffer, $0.2 \mu \mathrm{L}$ Hot Start Taq Polymerase (GenetBio, Daejeon, Korea), and $12.6 \mu \mathrm{L}$ double distilled water. The PCR reactions were carried out in the following steps: pre-denaturation at $94^{\circ} \mathrm{C}$ for 10 minutes, 35 cycles of $94^{\circ} \mathrm{C}$ for 30 seconds, annealing temperature $\left({ }^{\circ} \mathrm{C}\right)$ for each primer for 30 seconds (Supplementary Table S1), and $72^{\circ} \mathrm{C}$ for 30 seconds, and followed by final extension at $72^{\circ} \mathrm{C}$ for $10 \mathrm{~min}$ utes. Reaction was performed using either GeneAmp PCR system 2700 (Applied Biosystems, Foster City, CA, USA) or C1000TM Thermal Cycler (BioRad, Hercules, CA, USA). The PCR products were visualized by $2 \%$ standard agarose gels stained with ethidium bromide (GenetBio, Korea). Initially, DNA pools containing 3 individual samples were used for PCR and sequencing to screen polymorphisms of THRSP. The PCR-RFLP was applied to confirm 3 single nucleotide polymorphism (SNPs) and a 3-bp indel. Approximately, 15 $\mu \mathrm{L}$ of PCR product was digested with 2 units of each restriction enzyme (Supplementary Table S1) based on the protocol provided by company (New England Biolabs Inc., Ipswich, MA, USA). Furthermore, the digested PCR product was separated on $3 \%$ agarose gels to identify genotype variations (Supplementary Figure S1). The 9-bp indel was confirmed using DNA Chip for The Agilent 2100 Bioanalyzer (Agilent Technologies Inc., Santa Clara, CA, USA) by following company protocol (Supplementary Figure S2). In addition, eleven of SNPs were genotyped using standard protocol of Fluidigm 192.24 SNPtype Genotyping Technology (Fluidigm, South 
San Francisco, CA, USA).

Single marker association analysis

The phenotypic data of growth-related traits from the 585 $\mathrm{F}_{1}$ progeny were in normal distribution (Data not shown). Single marker association analyses between the selected DNA markers and the traits using the $\mathrm{F}_{1}$ progeny was conducted using the following linear mixed-model:

$$
\mathrm{Y}_{\mathrm{ijklmn}}=\mu+\mathrm{G}_{\mathrm{i}}+\mathrm{S}_{\mathrm{j}}+\mathrm{B}_{\mathrm{k}}+\mathrm{L}_{\mathrm{l}}+\mathrm{P}_{\mathrm{m}}+\varepsilon_{\mathrm{ijklmn}}
$$

where, $Y_{i j k l m n}$ is the phenotype of the $n^{\text {th }}$ animal, $\mu$ is overall mean, $G_{i}$ is the fixed effect of THRSP genotype $i, S_{j}$ is the fixed effect of sex $j, B_{k}$ is the fixed effect of batch $k, L_{1}$ is the fixed effect of line 1 , and $P_{m}$ is random additive polygenic effect of animal $\mathrm{m}, \boldsymbol{\varepsilon}_{\mathrm{ijk} \mathrm{kmn}}$ is the random residual associated with the $\mathrm{n}^{\text {th }}$ animal. The mean and variance for random additive polygenic effects can be defined as: $\mathrm{P} \sim N\left(0, \mathbf{A} \sigma_{\mathrm{a}}^{2}\right)$, where $\mathbf{A}$ is based on relationship matrix computed from the nuclear pedigree in this study and $\sigma_{\mathrm{a}}^{2}$ is the additive polygenic variance. The mean and variance for the residual random effect of individuals can be defined as: $\varepsilon \sim N\left(0, \mathbf{I} \sigma_{\mathrm{e}}^{2}\right)$, where $\mathbf{I}$ is the identity matrix and $\sigma_{\mathrm{e}}^{2}$ is the residual variance.

The significance level of fixed effects in the mixed-effects model above was computed by the Wald test in ASReml program (VSN International, Hemel Hempstead, UK). Nominal $\mathrm{p}<0.05$ was regarded as significant for all tests.

\section{Haplotype-based association analysis}

The $\mathrm{F}_{1}$ progeny were used to establish haplotypes at THRSP locus using the SNP markers showing nominal significance $(\mathrm{p}<0.05)$ for growth-related traits (Figure 1). The FImpute
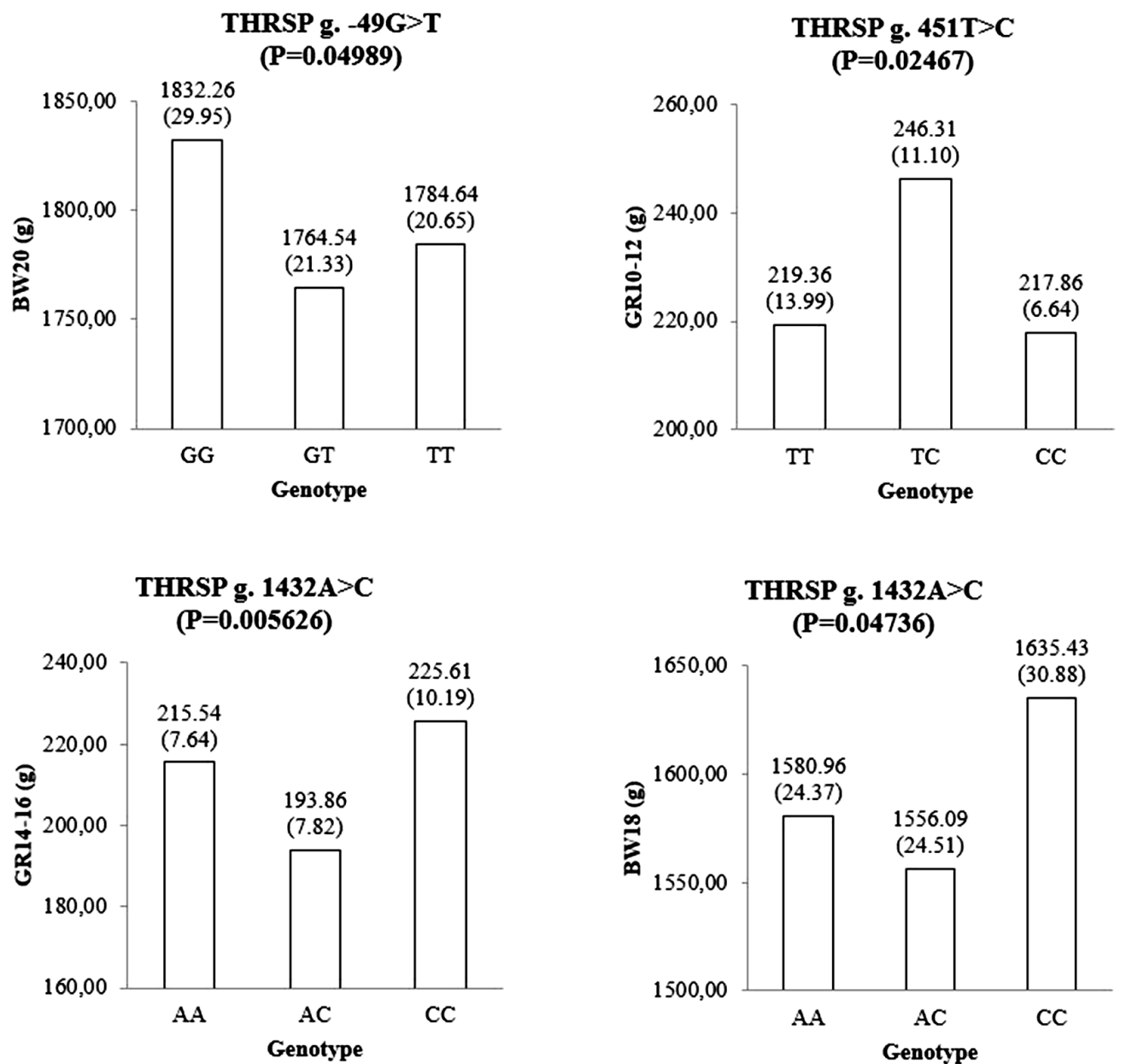

Figure 1. The genotypic means and standard errors of growth-related traits represent significant associations between the genotypes of the THRSP gene and growthrelated traits. p values were calculated using a mixed-effects model analysis. BW00 is body weight at birth; BW02 is body weight at 2 weeks of age; BW04 is body weight at 4 weeks of age; BW06 is body weight at 6 weeks of age; BW08 is body weight at 8 weeks of age; BW10 is body weight at 10 weeks of age; BW12 is body weight at 12 weeks of age; BW14 is body weight at 14 weeks of age; BW16 is body weight at 16 weeks of age; BW18 is body weight at 18 weeks of age; BW20 is body weight at 20 weeks of age; GRO-2 is body weight gain at 0 to 2 weeks of age; GR2-4 is body weight gain at 2 to 4 weeks of age; GR4-6 is body weight gain at 4 to 6 weeks of age; GR6-8 is body weight gain at 6 to 8 weeks of age; GR8-10 is body weight gain at 8 to 10 weeks of age; GR10-12 is body weight gain at 10 to 12 weeks of age; GR12-14 is body weight gain at 12 to 14 weeks of age; GR14-16 is body weight gain at 14 to 16 weeks of age; GR16-18 is body weight gain at 16 to 18 weeks of age; GR18-20 is body weight gain at 18 to 20 weeks of age. 
program based on pedigree information was applied to establish the haplotypes (REF. BMC Genomics 15, 478, 2014). Subsequently, the haplotype data of the $\mathrm{F}_{1}$ chickens were used to conduct haplotype-based association study. The effect of haplotypes on the traits of interests were evaluated by the following general linear model using the MINITAB program (MINITAB, State College, PA, USA):

$$
\mathrm{Y}_{\mathrm{ijklmn}}=\mu+\mathrm{D}_{\mathrm{i}}+\mathrm{S}_{\mathrm{j}}+\mathrm{B}_{\mathrm{k}}+\mathrm{L}_{\mathrm{l}}+\operatorname{Dam}_{(\mathrm{l}, \mathrm{m})}+\varepsilon_{\mathrm{ijklmn}}
$$

$\mathrm{Y}_{\mathrm{ijklmn}}$ is the phenotype of the $\mathrm{n}^{\text {th }}$ animal, $\mu$ is overall mean, $D_{i}$ is the fixed effect of THRSP diplotype $i$ (Table 1 ), $S_{j}$ is the fixed effect of sex $j, B_{k}$ is the fixed effect of batch $k, L_{l}$ is the fixed effect of line 1 , and $\operatorname{Dam}_{(1, \mathrm{~m})}$ is fixed effect of $\mathrm{m}^{\text {th }}$ dam within $1^{\text {th }}$ line, $\varepsilon$ is the random residual term of the model.

\section{RESULTS}

\section{Detection of polymorphisms in the THRSP gene}

Five sequences of THRSP were deposited in the National Center for Biotechnology Information (NCBI) website (GenBank accession numbers: KF574271-KF574275). A total of 30 polymorphisms were identified by aligning the sequences using ClustalW2 online software (http://www.ebi.ac.uk/Tools/ $\mathrm{msa} /$ clustalw2/). These variations were spread from upstream to downstream of the gene. Eleven SNPs and an 3-bp indel at 1,355 bp from ATG were found in the flanking regions and untranslated regions of the THRSP gene, thirteen SNPs and an 3-bp indel at 965 bp from ATG were identified in intron, and three SNPs were also observed in the exon 1 of the THRSP gene. In addition, an 9-bp indel at $236 \mathrm{bp}$ from start codon in the exon region of the THRSP gene which is identified in previous studies to be associated with body weight and abdominal fat traits in chickens was detected in present study (Table 1).

Table 1. Distribution of the THRSP gene polymorphism in Korean native chicken

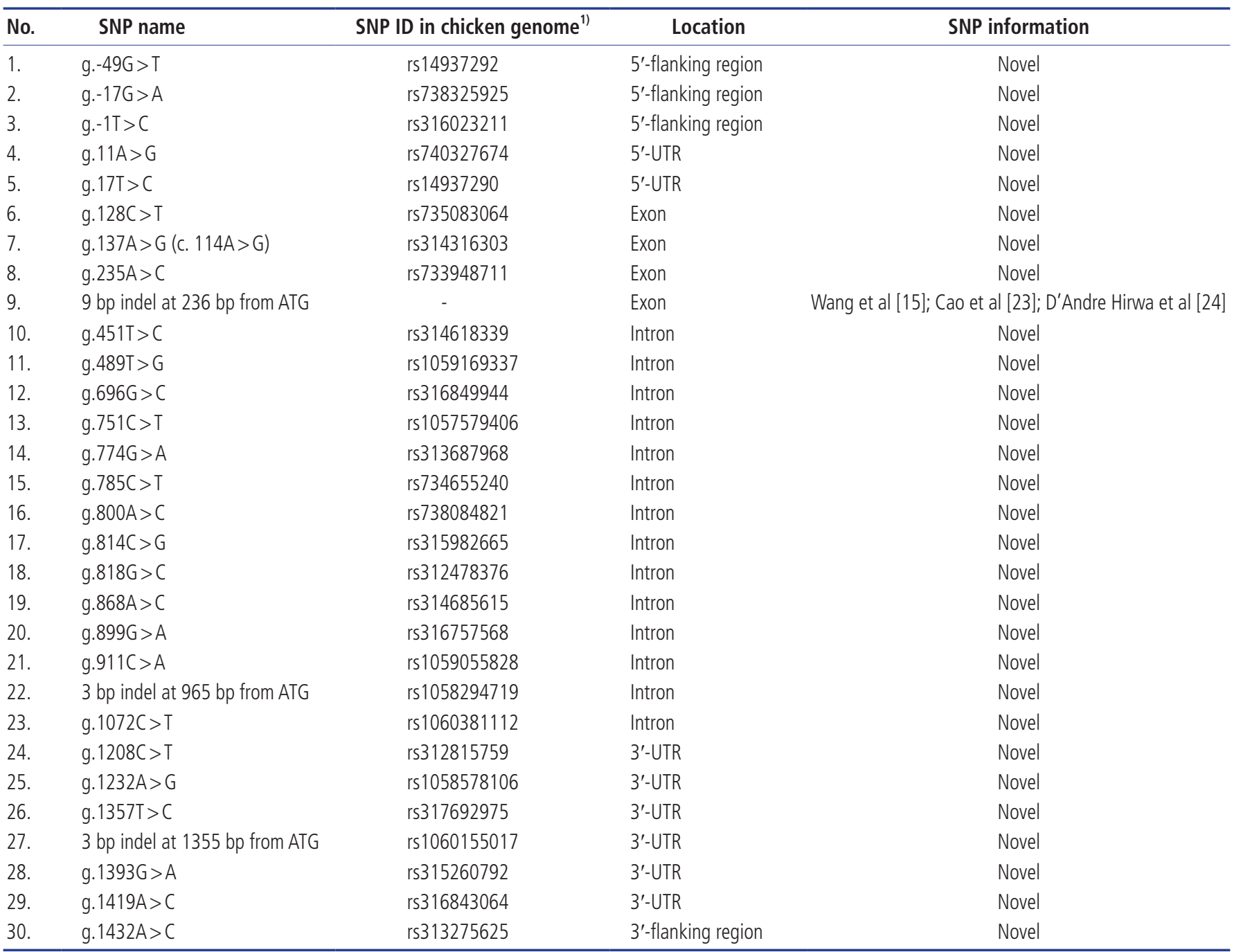

THRSP, thyroid hormone responsive spot 14 alpha; SNP, single nucleotide polymorphism.

1) SNP ID in the chicken genome was collected from Ensembl website (http://asia.ensembl.org/). 
The effects of the THRSP polymorphisms on growthrelated traits

A total of 30 polymorphisms in the THRSP gene have been identified in this study. Of these, nine polymorphisms were investigated to be associated with the body weight traits using a mixed-effects model in $585 \mathrm{~F}_{1} \mathrm{KNC}$ progeny. Among the SNP markers listed in the Table 1, a genotype call rate less than $90 \%$ was not used for further association studies. Three SNPs showed significant association with growth-related traits (Figure 1). The g.-49G $>$ T SNP of the THRSP gene was significantly associated with body weight at 20 weeks of age (BW20). Homozygote GG population had a higher BW20 than other genotypes. A SNP, namely g.451T>C, was also significantly associated with growth at 10 to 12 weeks (GR10-
12). Moreover, g.1432A $>\mathrm{C}$ was statistically associated with growth 14 to 16 weeks and body weight at 18 weeks. The CC genotype of the g.1432A $>$ C SNP was favorable for those traits. Additionally, four SNPs, namely g.-49G>T, g.696G $>$ C, g.1419A $>C$, and g.1432A $>C$, were suggestively associated with some growth-related traits in $\mathrm{F}_{1} \mathrm{KNC}$ population (Figure 2).

We also constructed haplotypes of the THRSP gene to evaluate the effect of the THRSP haplotype on growth-related phenotypes in the $F_{1}$ chicken population. Haplotype and diplotype frequencies of the THRSP gene in the $\mathrm{F}_{1}$ chickens are listed in the Table 2. The results of haplotype-based association analysis indicated that there were significant association between the diplotype and BW12. Ht1/ht2 dip-
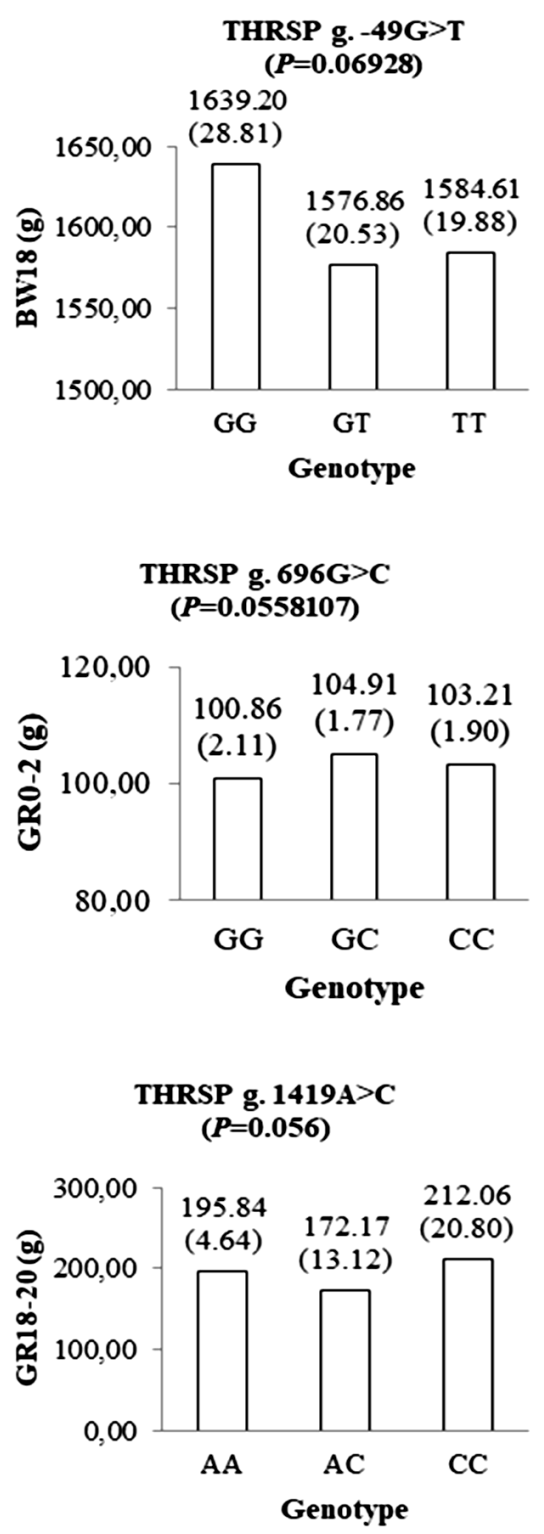
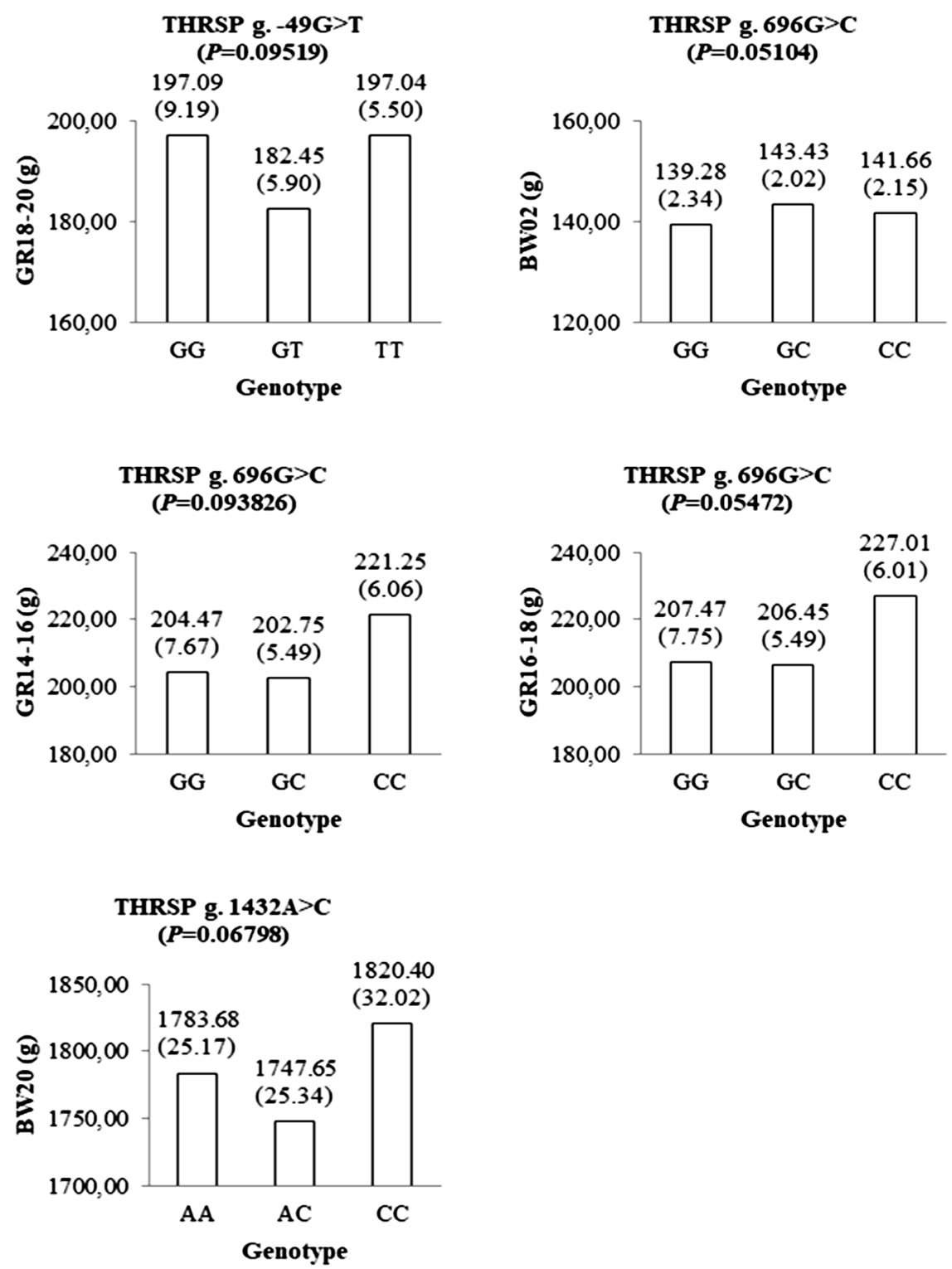

THRSP g. 696G $>C$ $(P=0.05104)$

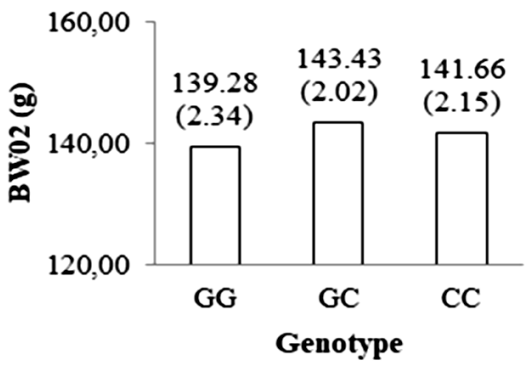

IRSP g. 696G $>C$

$6.01)$
Figure 2. The genotypic means and standard errors of growth-related traits represent suggestive-significant associations between the genotypes of the THRSP gene and growth-related traits. p values were calculated using a mixed-effects model analysis. THRSP, thyroid hormone responsive spot 14 alpha gene. 
Table 2. Haplotype and diplotype frequencies of the THRSP gene in the $F_{1}$ chickens

\begin{tabular}{|c|c|c|c|c|c|}
\hline Haplotype $^{1)}$ & Number & Frequency $^{2)}$ & Diplotype & Number & Frequency \\
\hline G-C-C (ht1) & 124 & 0.16 & ht1/ht1 & 53 & 0.137 \\
\hline G-T-A (ht2) & 95 & 0.122 & ht1/ht2 & 18 & 0.046 \\
\hline T-T-C (ht3) & 32 & 0.041 & $h t 3 / h t 3$ & 16 & 0.041 \\
\hline T-T-A (ht4) & 447 & 0.577 & ht4/ht4 & 196 & 0.505 \\
\hline G-T-C (ht5) & 28 & 0.036 & ht2/ht4 & 32 & 0.082 \\
\hline \multirow[t]{3}{*}{$\mathrm{T}-\mathrm{C}-\mathrm{C}(\mathrm{ht} 6)$} & 50 & 0.064 & $h t 5 / h t 6$ & 28 & 0.072 \\
\hline & & & ht4/ht2 & 23 & 0.059 \\
\hline & & & $h+6 / h t 2$ & 22 & 0.057 \\
\hline
\end{tabular}

THRSP, thyroid hormone responsive spot 14 alpha.

1) The 1st locus is THRSP g. $-49 \mathrm{G}>\mathrm{T}$, the 2 nd locus is THRSP g.451T $>C$, the 3rd locus is THRSP g. 1432A $>C$.

${ }^{2)}$ The haplotypes with frequency less than 0.03 are dropped in this table.

lotype was clearly favorable for BW12 (Table 3). Additionally, significant association of the diplotype with GR10-12 was detected in the $\mathrm{F}_{1}$ animals. Ht1/ht2 diplotype was also highest in growth at 10 to 12 weeks of age. Ht $4 / \mathrm{ht} 4$, where the most KNC population included in, was relatively moderate to high BW12 and GR10-12 traits (Table 3).

\section{DISCUSSION}

In this study, nine novel SNPs and a 9-bp indel reported previously were used for the association analyses. Interestingly, the genotypic value of the heterozygotes of the markers in Figure 1 and 2 showed dominance effects (i.e., deviation from the mean value of the two homozygotes) [28]. Therefore, no SNP with significant additive effect was detected in this study.

Significant associations were detected between g.-49G $>\mathrm{T}$ SNP, g.451T $>$ C, and g.1432A $>C$ with some growth-related traits in KNC. Those SNPs were located at 5'-flanking region, intron, and 3'-flanking region of THRSP gene. No exonic SNP showed significant association with growth related traits. Hence, expression levels might play an important role in the phenotypic variation of chicken growth. After transcrip-

Table 3. Effects of diplotype of the THRSP gene on BW12 and GR10-12 (LS means $\pm \mathrm{SE}$ )

\begin{tabular}{|c|c|c|c|c|}
\hline Diplotype & BW121) & $\mathrm{p}$-value & GR10-12 & p-value \\
\hline ht1/ht1 & $877.4 \pm 39.19^{a b}$ & 0.028 & $142.9 \pm 27.59^{a}$ & 0.007 \\
\hline ht1/ht2 & $1,024.9 \pm 44.63^{b}$ & & $278.3 \pm 31.41^{c}$ & \\
\hline ht3/ht3 & $1,001 \cdot 1 \pm 55.19^{a b}$ & & $278.3 \pm 38.85^{\mathrm{abc}}$ & \\
\hline ht4/ht4 & $997.0 \pm 17.16^{\mathrm{ab}}$ & & $248.2 \pm 12.08^{b c}$ & \\
\hline ht2/ht4 & $948.9 \pm 39.46^{\mathrm{ab}}$ & & $246.0 \pm 27.78^{\mathrm{abc}}$ & \\
\hline ht5/ht6 & $934.1 \pm 58.13^{a b}$ & & $169.7 \pm 40.92^{\mathrm{abc}}$ & \\
\hline ht4/ht2 & $1,001.9 \pm 46.17^{a b}$ & & $226.3 \pm 32.50^{\mathrm{abc}}$ & \\
\hline ht6/ht2 & $876.4 \pm 42.10^{a}$ & & $155.8 \pm 29.64^{\mathrm{ab}}$ & \\
\hline
\end{tabular}

THRSP, thyroid hormone responsive spot 14 alpha; SE, standard error.

1) $\mathrm{BW} 12$, body weight at 12 weeks of age.

2) GR10-12, growth at 10 to 12 weeks of age.

${ }^{a-c} L S$ means with different superscripts within same column are significantly different at $p<0.05$. tion factor binding motif analysis using MEME suite [29] and JASPAR database [30], we revealed that the position of g.-49G>T SNP is co-localized with MEF2D (myocyte enhancer factor-2D) binding motif sequence in the $5^{\prime}$-flanking region of the THRSP gene (i.e., g.-52 g.-47). Therefore, further expression studies can be worthwhile to characterize g.-49G>T SNP. Association results of the three significant SNPs and diplotypes indicated their possible role in controlling of body weight and growth traits of mature KNC.

Previous works showed that polymorphisms of the THRSP were associated with body weight, carcass traits, fat deposition, cholesterol and lipoprotein [15,23,24]. Particularly, A213C SNP was associated with body weight at 5 to 12 weeks of age and carcass weight, and two SNPs in $5^{\prime}$-flanking region were associated with body weight at hatch and BW at 28 days of age $[23,24]$. Indeed, the stronger effect of 9-bp indel has previously been discovered to be affecting body weight at 8 to 12 weeks of age and also carcass weight in chickens [23]. However, they were not confirmed in KNC population, except for an 9-bp indel in the exon region. There are several possible explanations for this discrepancy. First, the previously identified association may not be a direct effect of the polymorphisms but rather the result of linkage disequilibrium. Second, the effect of the polymorphisms on the body weight traits may be too small to be detected in our $\mathrm{F}_{1}$ nuclear families. In the case of previously reported associations found in chicken $\mathrm{F}_{2}$ intercross pedigrees $[23,24]$, they only used the general linear model procedure without including an additive relationship matrix to access the association between THRSP and body weight traits.

In conclusion, three novel SNPs in the THRSP gene were associated with body weight and growth-related traits in KNC. These results provided additional support for association between polymorphisms in the THRSP and growth-related traits. It could be useful to be developed as candidate gene for growth traits in $\mathrm{KNC}$ population. 


\section{CONFLICT OF INTEREST}

We certify that there is no conflict of interest with any financial organization regarding the material discussed in the manuscript.

\section{ACKNOWLEDGMENTS}

This work was supported by the Korea Institute of Planning and Evaluation for Technology in Food, Agriculture, Forestry and Fisheries through the Golden Seed Project, Ministry of Agriculture, Food and Rural Affairs (213010-05-4-SB250) and the "Cooperative Research Program for Agriculture Science \& Technology Development (PJ0128202020)" of the Rural Development Administration, Republic of Korea.

\section{REFERENCES}

1. Cahyadi M, Seo DW, Jin S, et al. Association of SNPs in ODC and PRDM16 with body weight traits in Korean native chicken. Korean J Poult Sci 2013;40:157-62. https://doi.org/10.5536/ KJPS.2013.40.2.157

2. Seo DW, Hoque MR, Choi NR, et al. Discrimination of Korean native chicken lines using fifteen selected microsatellite markers. Asian-Australas J Anim Sci 2013;26:316-22. https://doi. org/10.5713/ajas.2012.12469

3. Sang BD, Hong SK, Kim HK, et al. Estimation of genetic parameters for economic traits in Korean native chickens. AsianAustralas J Anim Sci 2006;19:319-23. https://doi.org/10.5713/ ajas.2006.319

4. Hoque MR, Lee SH, Jung KC, et al. Discrimination of Korean native chicken populations using SNPs from mtDNA and MHC polymorphisms. Asian-Australas J Anim Sci 2011;24: 1637-43. https://doi.org/10.5713/ajas.2011.11144

5. Manjula P, Park HB, Seo D, et al. Estimation of heritability and genetic correlation of body weight gain and growth curve parameters in Korean native chicken. Asian-Australas J Anim Sci 2018;31:26-31. https://doi.org/10.5713/ajas.17.0179

6. Cahyadi M, Jo C, Lee JH. Quantitative trait loci and candidate genes for the economic traits in meat-type chicken. Worlds Poult Sci J 2014;70:329-42. https://doi.org/10.1017/S004393 3914000348

7. Spencer GSG. Hormonal systems regulating growth. A review. Livest Prod Sci 1985;12:31-46. https://doi.org/10.1016/03016226(85)90038-7

8. Friedman JM, Halaas JL. Leptin and the regulation of body weight in mammals. Nature 1998;395:763-70. https:/doi.org/ $10.1038 / 27376$

9. Barsh GS, Farooqi IS, O'Rahilly S. Genetics of body-weight regulation. Nature 2000;404:644-51. https://doi.org/10.1038/ 35007519 https://doi.org/10.1038/35007519

10.Schutz Y. Dietary fat, lipogenesis and energy balance. Physiol
Behav 2004;83:557-64. https://doi.org/10.1016/j.physbeh.2004. 09.015

11. Fall T, Ingelsson E. Genome-wide association studies of obesity and metabolic syndrome. Mol Cell Endocrinol 2014;382:74057. https://doi.org/10.1016/j.mce.2012.08.018

12.Seelig S, Liaw C, Towle HC, Oppenheimer JH. Thyroid hormone attenuates and augments hepatic gene expression at a pretranslational level. Proc Natl Acad Sci USA 1981;78:47337. https://doi.org/10.1073/pnas.78.8.4733

13. Kinlaw WB, Church JL, Harmon J, Mariash CN. Direct evidence for a role of the "spot14" protein in the regulation of lipid synthesis. J Biol Chem 1995;270:16615-8. https://doi. org/10.1074/jbc.270.28.16615

14. Jump DB, Narayan P, Towle H, Oppenheimer JH. Rapid effects of triiodothyronine on hepatic gene expression: Hybridization analysis of tissue-specific triiodothyronine regulation of mRNAS14. J Biol Chem 1984;259:2789-97.

15. Wang X, Carre W, Zhou H, Lamont SJ, Cogburn LA. Duplicated Spot 14 genes in the chicken: characterization and identification of polymorphisms associated with abdominal fat traits. Gene 2004;332:79-88. https://doi.org/10.1016/j.gene. 2004.02.021

16. Chagnon YC, Perusse L, Bouchard C. The human obesity gene map: the 1997 update. Obes Res 1998;6:76-92. https:// doi.org/10.1002/j.1550-8528.1998.tb00318.x

17. Donnelly C, Olsen AM, Lewis LD, Eisenberg BL, Eastman A, Kinlaw WB. Conjugated linoleic acid (CLA) inhibits expression of the Spot 14 (THRSP) and fatty acid synthase genes and impairs the growth of human breast cancer and liposarcoma cells. Nutr Cancer 2008;61:114-22. http://dx.doi.org/10.1080/ 01635580802348666

18. Cogburn LA, Wang X, Carre W, et al. Systems-wide chicken DNA microarrays, gene expression profiling, and discovery of functional genes. Poult Sci 2003;82:939-51. https://doi.org/ $10.1093 / \mathrm{ps} / 82.6 .939$

19. Carre W, Diot C, Fillon V, et al. Development of 112 unique expressed sequence tags from chicken liver using an arbitrarily primed reverse transcriptase-polymerase chain reaction and single strand conformation gel purification method. Anim Genet 2001;32:289-97. https://doi.org/10.1046/j.1365-2052. 2001.00792.x

20.Ikeobi CON, Woolliams JA, Morrice DR, et al. Quantitative trait loci affecting fatness in the chicken. Anim Genet 2002; 33:428-35. https://doi.org/10.1046/j.1365-2052.2002.00911.x

21.Lagarrigue S, Pitel F, Carre W, et al. Mapping quantitative trait loci affecting fatness and breast muscle weight in meattype chicken lines divergently selected on abdominal fatness. Genet Sel Evol 2006;38:85. https://doi.org/10.1186/1297-968638-1-85

22. Ankra-Badu GA, Shriner D, Le Bihan-Duval E, et al. Mapping main, epistatic and sex-specific QTL for body composition in a chicken population divergently selected for low or high 
growth rate. BMC Genomics 2010;11:107. https://doi.org/10. 1186/1471-2164-11-107

23.Cao ZP, Wang SZ, Wang QG, Wang YX, Li H. Association of spot14 alpha gene polymorphisms with body weight in the chicken. Poult Sci 2007;86:1873-80. https://doi.org/10. 1093/ps/86.9.1873

24. d'Andre Hirwa C, Yan W, Wallace P, et al. Effects of the thyroid hormone responsive spot14a gene on chicken growth and fat traits. Poult Sci 2010;89:1981-91. https://doi.org/10.3382/ ps.2009-00582

25. Hoque MR, Lee SW, Lee JH. DNA markers in chicken for breed discrimination. CNU J Agric Sci 2012;39:211-7. https:// doi.org/10.7744/cnujas.2012.39.2.211

26. Cahyadi M, Park HB, Seo DW, et al. Variance component quantitative trait locus analysis for body weight traits in pure- bred Korean native chicken. Asian-Australas J Anim Sci 2016; 29:43-50. https://doi.org/10.5713/ajas.15.0193

27. Miller SA, Dykes DD, Polesky HF. A simple salting out procedure for extracting DNA from human nucleated cells. Nucleic Acids Res 1988;16:1215. https://doi.org/10.1093/ nar/16.3.1215

28. Falconer DS, Mackay TFC. Introduction to quantitative genetics. 4th ed. Harlow, UK: Addison-Wesley Longman; 1996.

29. Bailey TL, Boden M, Buske FA, et al. MEME SUITE: tools for motif discovery and searching. Nucleic Acids Res 2009;37: W202-8. https://doi.org/10.1093/nar/gkp335

30. Khan A, Fornes O, Stigliani A, et al. JASPAR 2018: update of the open-access database of transcription factor binding profiles and its web framework. Nucleic Acids Res 2018;46: D260-6. https://doi.org/10.1093/nar/gkx1126 